\title{
Laparoscopic or open appendicectomy for suspected appendicitis in pregnancy, evaluation of foetal outcome in Australia.
}

\author{
Nicole N Winter MBBS(Hons) BMedSci \\ Department of Surgery, Barwon Health \& Department of Specialist General Surgery, RMH \\ Glenn D Guest FRACS, MBBS, MSc
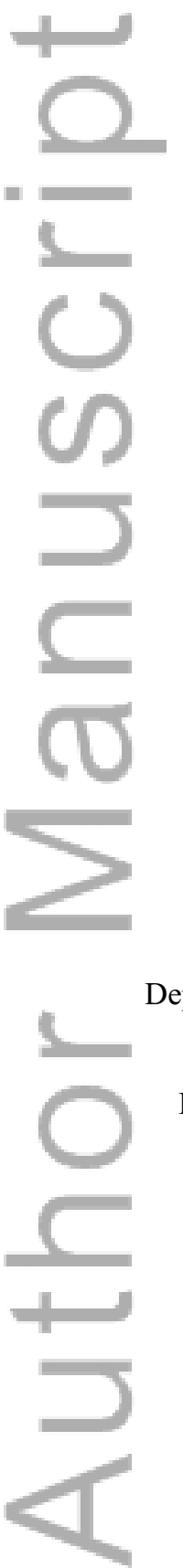 \\ Department of Surgery, Barwon Health \\ Michael Bozin MBBS, BMedSci \\ Benjamin N Thomson FRACS, MBBS \\ Department of Specialist General Surgery, RMH \\ G Bruce Mann MBBS, PhD, FRACS \\ The Breast Service, RWH, The University of Melbourne \\ Stephanie BM Tan MBBS \\ Department of Surgery, Royal Brisbane and Women's Hospital \\ David A Clark FRACS, MBBS \\ Department of Surgery, Royal Brisbane and Women's Hospital \\ Jurstine Daruwalla PhD, MBBS \\ Vijayaragavan Muralidharan PhD, FRACS, MBBS (Hons), BMedSci \\ The University of Melbourne, Department of Surgery, Austin Health \\ Neeha Najan MBBS \\ Meron E Pitcher FRACS, MBBS \\ Department of Surgery, Western Health \\ Karina Vilhelm MBBS \\ Department of Surgery, Nepean Hospital \\ Michael R Cox FRACS, MBBS, MS, \\ Department of Surgery, University of Sydney Clinical School, Nepean Hospital \\ Steven E Lane PhD, BSci(Hons) \\ Biostatistics Unit, Barwon Health; School of Medicine, Deakin University \\ David A Watters ChM FRCSEd FRACS \\ Deakin University, Department of Surgery, Barwon Health \\ Correspondence \\ Nicole N Winter \\ Department of Specialist General Surgery \\ $\mathrm{RMH}$ \\ Email: Nicole.gao1@gmail.com \\ No Disclosures/Scholarships \\ Word count: Abstract218 Text2730 \\ Figure1 Overview \\ Table1 Summary of Results \\ Table2 Case details of fetal loss in laparoscopic group
}

This is the author manuscript accepted for publication and has undergone full peer review but has not been through the copyediting, typesetting, pagination and proofreading process, which may lead to differences between this version and the Version of Record. Please cite this article as doi: 10.1111/ans.13750

This article is protected by copyright. All rights reserved. 


\section{Abstract}

Background: Recent data suggest that laparoscopic appendicectomy (LA) in pregnancy is associated with higher rates of foetal loss when compared to open appendicectomy (OA). However the influence of gestational age and maternal age, both recognized risk factors for foetal loss was not assessed.

Method: A multi-centre retrospective review of all pregnant patients who underwent appendicectomy for suspected appendicitis from 2000 to 2012 across seven hospitals in Australia. Perioperative data and foetal outcome were evaluated.

Results: Data on 218 patients from the seven hospitals were included in the analysis. 125 underwent LA and $93 \mathrm{OA}$. There were seven (5.6\%) foetal losses in the LA group, six of which occurred in the first trimester and none in the OA group. After matching using propensity scores, the estimated risk difference was 5.1\% (95\% CI: 1.4\%, 9.8\%). First trimester patients were more likely to undergo LA $(84 \%)$, while those in the third were more likely to undergo OA (85\%). Preterm delivery rates (6.8\% LA vs. 8.6\% OA; CI: $-12.6 \%$, $5.3 \%$ ) and hospital length of stay ( 3.7 days LA vs. 4.5 days OA; CI: -1.3, 0.2 days) were similar,

Conclusion: This is the largest published dataset investigating the outcome after LA versus OA while adjusting for gestational and maternal age. OA appears to be a safer approach for pregnant patients with suspected appendicitis.

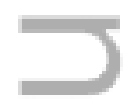

\section{Background}

This article is protected by copyright. All rights reserved. 
Abdominal pain in pregnancy is a diagnostic challenge. Although there are many potential causes, the most common reason to consider abdominal surgery is acute appendicitis. ${ }^{1,2}$ The literature suggests the rate of suspected appendicitis is approximately 1:635 to 1:500 pregnancies. The true incidence of pathologically proven appendicitis is in the order of $1: 1440 .^{3}$ The background rate of appendicitis during pregnancy is similar to that of nonpregnant women, however appendiceal perforation rates may be higher in the gravid population. ${ }^{4}$ With perforation, foetal loss occur in $20 \%$ of cases, compared with $1.5 \%$ for uncomplicated appendicitis. ${ }^{5}$ Similarly, perforation can be associated with preterm-labour and increased perinatal and maternal morbidity. ${ }^{6,7}$ The anatomical and physiological changes in pregnancy create challenges to the clinical assessment, investigations and decision making. Due to these reasons, a more aggressive surgical strategy is often chosen, resulting in a higher negative appendicectomy rate in pregnant women $(27 \%$ vs. $18 \%){ }^{8}$

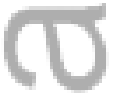

The safest surgical approach for suspected appendicitis in pregnancy remains controversial. Multiple large series attest to the safety of laparoscopic surgery in pregnancy, despite earlier concerns relating to changes in intra-abdominal pressures and relative hypercarbia. ${ }^{9}$ Most previous studies looking at open vs. laparoscopic appendicectomy in pregnancy were underpowered to detect any benefit of either surgical approach, resulting in conflicting conclusions. However, a recent systematic review by Wilasrusmee ${ }^{10}$ pooled these studies and found there was a statistically significant increase in the risk of foetal loss in the laparoscopic group compared with open surgery (RR 1.91). Preterm labour rates, hospital length of stay (LOS) and perinatal complications were similar. 
The Wilasrusmee review was heavily influenced by one paper (contributing $87.65 \%$ of the data). This study was a retrospective analysis of case files from California, which did not account for maternal and gestational age - both independent determinants of foetal loss rates. Furthermore, gestational age is a likely determinant in surgical approach and hence a significant confounder in this study.

We hypothesized that the LA group would have an over representation of early gestational ages compared with the OA and accordingly, the difference in risk of foetal loss between LA and OA may be explained by the inherently higher risks of foetal loss earlier in pregnancy. In order to more accurately determine the influence of surgical approach, we sought to evaluate the risks of foetal loss in pregnant woman following laparoscopic or open appendicectomy for suspected appendicitis adjusting for these factors.

\section{Methods}

This analysis consisted of a multicentre retrospective review of all pregnant patients who underwent surgery for suspected appendicitis from 2000 to 2012 in the participating centres. Seven hospitals across Australia participated in this review including Austin Health, Barwon Health, Nepean Hospital, Royal Brisbane and Women's Hospital, Royal Melbourne Hospital, Royal Women's Hospital, and Western Health. Patients were identified using Medicare Benefits Schedule coding (30572-LA, 30571-OA) and ICD-9/10 coding ( $\mathrm{Z}$ or $\mathrm{O}$ ) for pregnancy during the same admission. Study inclusion criteria were pregnant patients who had either LA or OA. Gestational date was identified by preoperative ultrasound imaging in 
their history. If this was not available, estimated gestational date documented by the treating obstetric team was used. Data were collected from medical records at each centre and deidentified. This de-identified data was then given a generated study code and transferred electronically to the principal investigator.

Where obstetric outcome was incomplete (patients who did not deliver at the same hospital ares they presented for suspected appendicitis) the patient's general practitioner (GP) was contacted. The GP interview consisted of standard questions to determine rates of foetal loss, preterm labour and foetal malformation. The data were then recorded on the same data sheet. If the GP declined participation, the patient's obstetrics outcome was recorded as N/A, and the patient was excluded.

Data were collected in three streams: Preoperative, Operative and Postoperative. Preoperative data included date of surgery, maternal age, comorbidities and gestational age. Operative data included laparoscopic or open surgery; if laparoscopic, the entry-type, conversion to open and the reason, operative diagnosis, intraoperative complications, and primary surgeon (i.e. registrar, fellow, and consultant). Postoperative data included pathological diagnosis, postoperative complications, maternal mortality, foetal loss at 30 days, foetal loss $>30$ days, preterm delivery ( $<37$ weeks), term delivery (e 37 weeks gestation), hospital LOS and major foetal malformations. 
The primary outcome was foetal loss in relation to surgical approach, with secondary outcomes being preterm delivery and LOS. Differences in outcomes were estimated as average treatment effects, by matching on propensity scores. A matched approach was taken because of the low numbers of foetal loss that occurred exclusively in the LA group. Propensity scores were calculated by boosted logistic regression ${ }^{11,12}$ including terms for maternal age, gestational age, experience level of the surgeon performing the operation, maternal comorbidities, the hospital at which the procedure was performed, the year the procedure was performed and the para status of the patient $(\mathrm{G}>1, \mathrm{P}=0)$. Laparoscopic surgery patients were then matched to patients who underwent open surgery by replacement. The average treatment effect and 95\% CI were calculated by nonparametric bootstrap.

\section{Results}

During the study period, at the seven participating hospitals, 264 patients were identified. 18 patients were excluded due to alternative diagnosis or indications for surgery (nine underwent lower uterine segment caesarean section and appendicectomy, three had an elective oncological procedure during pregnancy, two patients were already postpartum, two were incorrectly coded, one case of ectopic pregnancy, and one case of small bowel resection for Meckel's diverticulitis). 18 had missing foetal outcome data; nine due to elective termination of pregnancy (eight LA, one LA converted to OA due to equipment failure) and one conversion to midline laparotomy. This left 218 eligible patients: 125 LA, 93 OA (Figure 1). Five patients who underwent laparoscopic procedures, but later converted to open were classified as LA for the purposes of our review because they were still exposed to the 
conditions of pneumoperitoneum. There were no foetal losses in this subgroup.

Summary of results are presented in Table 1. Maternal age and para status were similar between the two groups, but the median gestational age was lower in the LA group by nine weeks. First trimester patients were more likely to undergo LA $(84 \%)$ compared to OA, while third trimester were more likely to undergo $\mathrm{OA}(85 \%)$.

There were seven cases of foetal loss, giving an unadjusted risk difference 5.6\% (95\% CI: $1.5 \%-11.1 \%$ ), all of which occurred in the LA group. There were no cases of foetal loss in the OA group. Due to no foetal death identified in the open group, adjustment in a regression model was not possible. After matching using propensity scores, the estimated risk difference was $5.1 \%(95 \% \mathrm{CI}: 1.4 \%, 9.8 \%)$. Of the seven foetal losses, six occurred in the first trimester (4-13 weeks), with one occurring in the second trimester (Table 2). Rates of preterm delivery were similar between the two groups $(6.8 \% \mathrm{LA}$ vs. $8.6 \% \mathrm{OA}, 95 \% \mathrm{CI}$ for the difference: $12.6 \%, 5.3 \%$ ), as was hospital $\operatorname{LOS}(3.7$ days vs. 4.5 days, $95 \%$ CI for the difference: $-1.3,0.2$ days).

Consultant surgeons were less likely to be primary surgeon in the LA group (42\%) compared with OA (66\%). Complex appendicitis had a higher rate of foetal loss than normal and suppurative appendicitis. The appendix was classified as normal in 57 patients (26\%), acute suppurative appendicitis in 127 (58\%) and complicated/perforated in 34 (16\%). Two (3.5\%) episodes of foetal loss occurred in the normal group, three $(2.4 \%)$ in the simple appendicitis group and two $(5.9 \%)$ in the complicated perforated group. 


\section{Discussion}

In Australian hospitals more than $80 \%$ of patients presenting with suspected appendicitis will have a laparoscopic approach. ${ }^{13}$ Given the high degree of safety of laparoscopic procedures in pregnancy in prior reports ${ }^{10,14,15}$, and guidelines attesting to its safety ${ }^{16}$, Wilasrusmee's systematic review challenged the trend over the last decade towards the laparoscopic approach for suspected appendicitis in pregnancy. They found that LA was associated with RR 1.91 for foetal loss compared with OA. They included 11 studies with a total of 3415 women, of which 3133 patients were from McGory et al interrogating a large population database in California based on ICD-9 coding. Gestational age, a known determinant of foetal loss, was not available through this coding system and was omitted from McGory's analysis. Its primary outcome of early/preterm delivery was defined by ICD-9 coding of "caesarian section" and "hysterectomy", thus also omitting women who may have undergone preterm vaginal delivery. Another systematic review by Walsh et al reached similar conclusions regarding higher foetal loss rates in LA, however it also included McGory's data. Our findings however still support those of McGory and Wilasrusmee.

There are a number of risk factors for miscarriage and foetal loss, one of which is gestational age, with up to $80 \%$ of all miscarriages occurring before 12 weeks. ${ }^{18}$ Foetal loss rates by gestational age have been estimated as follows: First trimester $10-22 \%$, second trimester $0.5 \%-1 \%$ and $<0.5 \%$ in the third trimester. ${ }^{17,18}$ Moreover, within the first trimester, foetal loss rates decrease with each subsequent week, with one study reporting a drop from $10 \%$ at 6 weeks, to $0.7 \%$ at 10 weeks. ${ }^{19}$ It is within this context that we sought to explore the relationship that gestational age bore to foetal loss rates within our patient group. 
Maternal age is another major risk factor for miscarriage. The risk of foetal loss increases after the age of 35 years, rising from $9 \%$ at $20-24$ years to $75 \%$ at 45 years and older. ${ }^{20}$ Other documented but less significant factors include: increasing paternal age, extremes of BMI, indicators of stress, high alcohol consumption and obstetric factors, which include previous miscarriages, infertility issues and assisted conception. ${ }^{21,22}$ From interrogation of hospital records, we were able to analyse maternal age, parity (and previous miscarriage), and document the presence of comorbidities that may affect pregnancy.

Adjusting for these confounders, our study still found a higher rate of foetal loss in the LA group, with no foetal loss in the OA. Table 2 shows the demographic data and case details regarding each case of foetal loss. Five cases occurred in patients with gestational age $<7$ weeks, where the background rate of foetal loss is estimated at $10 \%-20 \%$. Only two cases had foetal loss within the first week postoperatively, the remaining five cases had foetal loss occurring at 2-5 weeks. Two of these cases had complicated appendicitis with persisting intraabdominal infection. Whilst in the majority of the cases the timing of foetal loss was later than expected and potentially explained via another cause, the same trends did not occur in the OA group. The exact mechanism for this is still unclear.

Despite these apparent trends from the raw data and possible explanations for a higher rate of foetal loss in the LA group, performing a more detailed statistical analysis involving propensity matching for gestational age, maternal age and para status, there was still a risk difference of $5.1 \%$ between LA and OA (CI: 1.4, 9.8). The limitation here was the number of events that happened - because appendicitis during pregnancy is rare, and subsequent foetal mortality even more rare, we did not have enough events to estimate the adjusted risk ratio in 
a regression model. This highlights that despite our efforts to collect data from multiple sites, due to the rarity of the event, only 218 cases in 12 years were identified. It is also notable that no foetal loss occurred in the OA group, which is well below the predicted foetal loss rate for pregnancy without surgical intervention. An explanation for this "protective" effect of OA eludes the authors and makes interpretation of the data even more complex.

Propensity score matching (PSM) is a statistical matching technique that attempts to estimate the effect of a treatment or intervention by accounting for the covariates that predict receiving the treatment. ${ }^{23}$ In this study, being in the first trimester is likely to predict receiving a laparoscopic approach. PSM attempts to reduce the bias due to confounding variables in an estimate of the treatment effect obtained from simply comparing outcomes among groups that received the treatment versus to those that did not. For our study, these included seniority of surgeon, the hospital and year in which the surgery took place and maternal comorbidities.

There is consensus within the surgical literature that surgical procedures, both laparoscopic and open, are safest when performed in the second trimester. During the first trimester, when organ development is occurring, teratogenicity of medications and decreased uterine blood flow due to general anaesthesia and pneumoperitoneum predispose to greater risk of foetal loss. In contrast, by the third trimester, the uterus occupies the majority of the abdominal cavity pushing the appendix into the right upper quadrant. Pneumoperitoneum, surgical access complexity are greatly increased and some institutions consider the third trimester a contraindication to LA. ${ }^{24}$ The literature confirms that open procedures are favoured during the third trimester, while laparoscopic are preferred for the first trimester. ${ }^{25,26}$ Gestational age is 
an important confounder that must be adjusted for when analysing foetal loss rates in pregnant women undergoing appendicectomy. The highest rate of miscarriage occurs during the first trimester even without any surgical intervention, and laparoscopic procedures are more likely to be performed during the 1 st trimester than later on in pregnancy.

When we looked at preterm labour rates, these were higher in the OA group, though this failed to achieve statistical significance. This trend may be the result of a higher proportion of appendicectomies being performed open in the third trimester. Were the same outcome to occur during the first or most of the second trimester, this would result in foetal loss rather than pre-term delivery.

LA in the general population with suspected appendicitis results in a shorter LOS compared to OA. Although a similar trend was seen in this study in the pregnant population (LA:

3.7days; OA: 4.5days), this did not reach statistical significance. Perioperative foetal monitoring rather than any surgical issue may be a plausible explanation for the longer length of stay in both groups and the lack of advantage of LA.

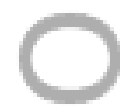

Two possible confounders we did not adjust for is the type of anaesthesia and the use of tocolytics. Propensity matching for hospital and year of procedure may partially account for this. Tocolytics are potentially beneficial in the setting of threatened preterm labour, however they are not recommended as prophylaxis in all pregnant women undergoing non-obstetrics surgery, especially in the first trimester. ${ }^{27}$ These two factors probably had very little influence on our results given six of the seven foetal loss identified were in the first trimester. 
While our numbers are not large, they still showed a clinically relevant trend regarding the safety of LA in pregnancy. This difference does not appear to be explained by the confounding factors of gestational or maternal age thus supporting the possibility that laparoscopic approach is an independent risk factor for foetal loss. Statistical matching allowed a better balance to be found between the two procedural groups, however as with all matching procedures this was not perfect. Yet, when our data is analysed with the existing data, there appears to be an increased risk of foetal loss when the procedure is performed by laparoscopy. The authors had originally expected that LA would be as safe as OA, but our data showed clinically relevant foetal risk.

Foetal loss following appendicectomy for suspected appendicitis is rare. Larger numbers are needed to more confidently ascertain the real risk of the surgical approach to appendicitis during pregnancy. A multicentre randomised control trial to answer this question in this patient group would be ethically challenging and difficult to run. The next step would be a larger, retrospective national study. Based on a relative risk of foetal loss of 1.9 in LA group, a relative risk of foetal loss in OA being approximately 50\% that of LA, and an estimated incidence of $7 \%$ ( arm.

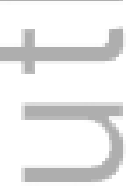

\section{Conclusion}


This is the largest published dataset looking at LA versus OA that controls for gestational age and maternal age in pregnant patients with suspected appendicitis. Whilst the mechanisms remain unclear, our data has shown that patients undergoing LA have a higher rate of foetal loss when compared to OA independent of these factors.

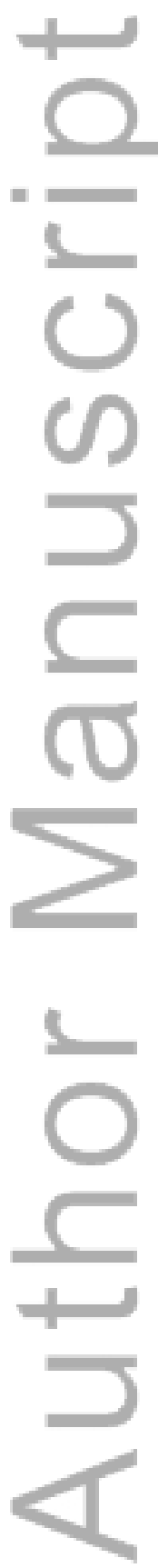

This article is protected by copyright. All rights reserved. 


\section{References}

${ }^{1}$ Kort B, Katz VL, Watson WJ. The effect of nonobstetric operation during pregnancy.Surg Gynecol Obstet 1993; 177:371-376.

${ }^{2}$ Guttman R, Goldman RD, Koren G. Appendicitis during pregnancy.Can Fam Physician 2004; 50:355-357.

${ }^{3}$ Mazze RI, KallenB. Appendectomy during pregnancy: a Swedish registry study of 778 cases.Obstet Gynecol 1991;77:835-840.

${ }^{4}$ Bisharah M, Tulandi T. Laparoscopic surgery in pregnancy.Clin Obstet Gynecol 2003; 46:92-97.

${ }^{5}$ Fallon WFJ, Newman JS, Fallon GL, et al. The surgical management of intra-abdominal inflammatory conditions during pregnancy.Surg Clin North Am 1995; 75:15-31

${ }^{6}$ McGory ML, Zingmond DS, Tillou A, et al.Negative appendectomy in pregnant women is associated with a substantial risk of fetal loss.J Am Coll Surg 2007; 205:534-540.

${ }^{7}$ Lemaire BMD, Van Erp WFM.Laparoscopic surgery during pregnancy.Surg Endosc 1997; 11:15-18.

${ }^{8}$ Walsh CA, Tang T, Walsh SR. Laparoscopic versus open appendicectomy in pregnancy: a systematic review.Int J Surg 2008; 6:339-344.

${ }^{9}$ Reedy MB, Källén BB, Kuehl TJ. Laparoscopy during pregnancy: a study of five fetal outcome parameters with use of the Swedish Health Registry.Am J Obstet Gynecol 1997;177(3):673-9.

This article is protected by copyright. All rights reserved. 
${ }^{10}$ Wilasrusmee C, Sukrat, B, McEvoy, M, et al. Systematic review and meta-analysis of safety of laparoscopic versus open appendicectomy for suspected appendicitis in pregnancy. Br J Surg 2012;99:1470-1478.

${ }^{11} R$ : A Language and Environment for Statistical Computing [computer program]. $\mathrm{R}$ Foundation for Statistical Computing,Vienna, Austria; 2011.

${ }^{12}$ Ridgeway G, et al. gbm: Generalized Boosted Regression Models.R package version $2.1 ; 2014$

${ }^{13}$ Suen K, Hayes IP, Thomson BN, et al. Effect of the introduction of an emergency general surgery service on outcomes from appendicectomy.Br J Surg 2014;101(1):e141-6

${ }^{14}$ Affleck DG, Handrahan DL, Egger MJ, et al. The laparoscopic management of appendicitis and cholelithiasis during pregnancy.Am J Surg 1999;178:523-529.

${ }^{15}$ Rollins MD, Chan KJ, Price RR. Laparoscopy for appendicitis and cholelithiasis during pregnancy: a new standard of care.Surg Endosc 2003;18(2):237-41.

${ }^{16}$ Korndorffer JR Jr, Fellinger E, Reed W. SAGES guideline for laparoscopic appendectomy. Surg Endosc 2010;24;757-761.

${ }^{17}$ Garcia-Enguidanos A, Calle ME, Valero J, et al. Risk factors in miscarriage: a review.Eur J Obstet Gynecol Reprod Biol 2002;102:111-19.

${ }^{18}$ Savitz DA, Hertz-Picciotto I, Poole C, et al. Epidemiologic measures of the course and outcome of pregnancy.Epidemiol Rev 2002;24:91-101.

${ }^{19}$ Tong S, Kaur A, Walker SP, et al.Miscarriage risk for asymptomatic women after a normal first-trimester prenatal visit.Obstet Gynecol 2008;111:710-714.

${ }^{20}$ Nybo Andersen AM, Wohlfahrt J, Christens P, et al. Maternal age and fetal loss: population based register linkage study.BMJ 2000;320(7251):1708-12.

This article is protected by copyright. All rights reserved. 
${ }^{21}$ Maconochie N, Doyle P, Prior S, et al. Risk factors for first trimester miscarriage--results from a UK-population-based case-control study.BJOG 2007;114:170-86.

${ }^{22}$ Hahn KA, Hatch EE, Rothman KJ, et al. Body Size and Risk of Spontaneous Abortion among Danish Pregnancy Planners.Paediatr Perinat Epidemiol 2014;28:412-423.

${ }^{23}$ Rosenbaum PR, Rubin DB. The central role of the propensity score in observational studies for causal effects.Biometrika,1983;70(1):41-55.

${ }^{24}$ Kirshtein B, Perry ZH, Avinoach E, et al. Safety of laparoscopic appendectomy during pregnancy. World J Surg 2009;33:475-480.

${ }^{25}$ Sadot E, Telem DA, Arora M, et al. Laparoscopy: a safe approach to appendicitis during pregnancy.Surg Endosc 2010;24:383-389.

${ }^{26}$ Corneille MG, Gallup TM, Bening T, et al. The use of laparoscopic surgery in pregnancy: evaluation of safety and efficacy.Am J Surg 2010;200:363-367.

${ }^{27}$ Berkman ND, Thorp JM Jr, Lohr KN, et al. Tocolytic treatment for the management of preterm labor: a review of the evidence.Am J Obstet Gynecol 2013; 88:1648-1659.

This article is protected by copyright. All rights reserved. 
Table 1 Summary of results, data presented as median (IQR), $\mathrm{n}$ and \% as appropriate

\begin{tabular}{|c|c|c|c|c|}
\hline & \multicolumn{2}{|c|}{ Open $(n=93)$} & \multicolumn{2}{|c|}{ Laparoscopic $(n=125)$} \\
\hline Maternal age (years, IQR) & 28 & $(24,32)$ & 27 & $(23,31)$ \\
\hline Gestational age (weeks, IQR) & 22 & $(16,28)$ & 13 & $(9,20)$ \\
\hline Comorbidities present (yes, \%) & 30 & $(32 \%)$ & 59 & $(47 \%)$ \\
\hline Para status $(\mathrm{G}>1, \mathrm{P}=0),($ no, $\%)$ & 83 & $(89 \%)$ & $107 / 123$ & $(87 \%)$ \\
\hline First Trimester (d13weeks) & 13 & $(16 \%)$ & 67 & $(84 \%)$ \\
\hline Second Trimester ( $>13$ to 28 weeks $)$ & 58 & $(52 \%)$ & 54 & $(48 \%)$ \\
\hline Third Trimester (>28weeks) & 22 & $(85 \%)$ & 4 & $(15 \%)$ \\
\hline Foetal loss & 0 & $(0 \%)$ & 7 & $(5.6 \%)$ \\
\hline Preterm delivery & 8 & $(8.6 \%)$ & $8 / 117$ & $(6.8 \%)$ \\
\hline Length of stay (days, sd) & 4.5 & $(2.8)$ & 3.7 & $(2.0)$ \\
\hline
\end{tabular}

$\mathrm{IQR}=$ interquartile range
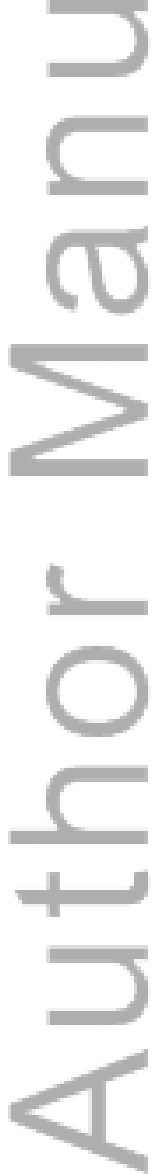

This article is protected by copyright. All rights reserved. 


\begin{tabular}{|c|c|c|c|c|c|}
\hline & $\begin{array}{l}\text { Gestational } \\
\text { age }\end{array}$ & G & $\mathbf{P}$ & Pathology & Timing of foetal loss \\
\hline \multirow{4}{*}{$1^{\text {st }}$} & 4 weeks & 4 & 2 & Normal appendix & 48 hours postop \\
\hline & 6 weeks & 2 & 0 & $\begin{array}{l}\text { Perforated gangrenous } \\
\text { appendicitis }\end{array}$ & Septic 3 weeks post op \\
\hline & 6 weeks & 4 & 1 & Normal appendix & 2 weeks post op \\
\hline & 7 weeks & 4 & 1 & Acute suppurative appendicitis & 1 week post op \\
\hline . & 7 weeks & 4 & 0 & Acute suppurative appendicitis & 5 weeks post op \\
\hline & 13 weeks & 5 & 0 & Acute suppurative appendicitis & 4 weeks post op \\
\hline $\begin{array}{c}2^{\text {nd }} \\
\text { Trimester } \\
\end{array}$ & 21weeks & 2 & 1 & $\begin{array}{l}\text { Perforated appendicitis with } \\
\text { pelvic abscess }\end{array}$ & RTT 2 weeks post op \\
\hline
\end{tabular}

This article is protected by copyright. All rights reserved. 


\section{University Library}

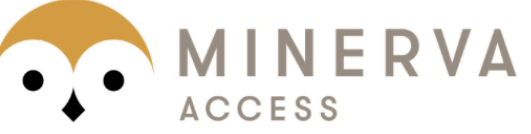

A gateway to Melbourne's research publications

Minerva Access is the Institutional Repository of The University of Melbourne

\section{Author/s:}

Winter, NN;Guest, GD;Bozin, M;Thomson, BN;Mann, GB;Tan, SBM;Clark, DA;Daruwalla, J;Muralidharan, V;Najan, N;Pitcher, ME;Vilhelm, K;Cox, MR;Lane, SE;Watters, DA

Title:

Laparoscopic or open appendicectomy for suspected appendicitis in pregnancy and evaluation of foetal outcome in Australia

Date:

2017-05-01

Citation:

Winter, N. N., Guest, G. D., Bozin, M., Thomson, B. N., Mann, G. B., Tan, S. B. M., Clark, D. A., Daruwalla, J., Muralidharan, V., Najan, N., Pitcher, M. E., Vilhelm, K., Cox, M. R., Lane, S. E. \& Watters, D. A. (2017). Laparoscopic or open appendicectomy for suspected appendicitis in pregnancy and evaluation of foetal outcome in Australia. ANZ JOURNAL OF SURGERY, 87 (5), pp.334-338. https://doi.org/10.1111/ans.13750.

Persistent Link:

http://hdl.handle.net/11343/291696 